CIC. Cuadernos de Información y Comunicación ISSN: 1135-7791

http://dx.doi.org/10.5209/CIYC.55968

\title{
El lenguaje digital, una gramática generativa
}

\author{
Eva Aladro Vico ${ }^{1}$
}

Enviado: 11 de octubre de 2016 / Aceptado: 23 de octubre de 2016

Resumen. Este texto es una investigación en profundidad sobre las composiciones digitales de múltiples elementos que aquí son considerados un único lenguaje digital. Siguiendo la idea de Manovich, reflexionamos sobre cómo este lenguaje trabaja con una gramática transformacional o generativa cuyos elementos fundamentales y operaciones básicas se centran en el uso de lenguaje previos en operaciones proyectivas y metaforizantes, así como en fusiones conceptuales, que utilizan las estructuras profundas de las gramáticas de los medios del siglo XX para producir composiciones creativas en transformación constante. Se enuncian algunas de las matrices y metáforas fundamentales de este lenguaje como el mapa escalable, el contenedor, las metáforas ontológicas y las orientacionales y espaciales.

Palabras clave: gramática generativa; lenguaje digital; metáfora y analogía; mapas y proyecciones;matrices de analogía; lenguajes de los medios.

\section{[en] The digital language, a generative grammar}

Abstract. This paper focuses on a researching reflection about the digital compositions of multiple elements and media which are considered as a unique digital language, following the idea by Lev Manovich. Taking one step more, we reflect about how this new digital language works too with a generative or transformational grammar, and we discuss the main elements and traits of the transformational digital grammar. Some transformational operations such as mapping, metaphor and analogy, and conceptual blending, act to retrieve the universal media deep structures and to produce the performances in the dynamic and creative use and development of the web's language. We consider some of the main matrix of this creative transformations such as the scalable map, the container metaphor, the analogies and metaphors of bodily and positional experiences, and the conceptual blending of various dimensions of language and action.

Keywords: transformational grammar; digital language; Manovich; Chomsky; metaphor theories; conceptual blending; mapping, language; Web.

Sumario. Recordando la gramática transformacional. El software y el lenguaje digital como gramática generativa. El lenguaje digital. Mecanismos fundamentales. La matriz metafórica del lenguaje digital: el mapa escalable. Metáforas, proyecciones y fusiones de la gramática universal digital. Métáforas fundamentales. Proyecciones fundamentales. Fusiones conceptuales. Conclusiones. Bibliografía.

Cómo citar: Aladro Vico, E. (2017). El lenguaje digital, una gramática generativa, en CIC. Cuadernos de Información y Comunicación 22, 79-94.

Este artículo tiene por objetivo lanzar la idea de que el lenguaje de los nuevos medios digitales es una entidad unitaria, un lenguaje de lenguajes que responde a los

1 Universidad Complutense de Madrid

Email: ealadro@ucm.es 
mecanismos y procesos característicos descritos hace ya medio siglo en la teoría de la gramática generativa y sus mecanismos transformacionales.

Ofrecemos esta concepción de la convergencia digital como la conformación de un nuevo lenguaje generativo, porque ayuda a comprender los mecanismos de convergencia, transcodificación e hibridación continua de las formas comunicativas provenientes de muy diferentes lenguajes y sistemas de señales previos, como son el propio lenguaje verbal, el lenguaje visual, el lenguaje gestual e interpersonal relacionado con sistemas kinestésicos y también otras formas expresivas asociadas al uso de herramientas en distintos medios y sistemas de comunicación, de muy diferentes épocas y periodos.

Como sabemos, todas estas fuentes de formas expresivas confluyen en un sistema emulador que con enorme capacidad generativa está constituyendo un "meta-medio", en expresión de Lev Manovich (2005a), y propiamente, un lenguaje de medios, en tanto todo lenguaje es necesariamente un sistema que engloba y traduce otros lenguajes previos, constituyendo su núcleo esencial dicho sistema traductor (Lotman 1988), en su sistema de transformaciones. Vamos a estudiar en detalle estas ideas.

Debemos entender las primeras formulaciones del lenguaje hipertextual, de la gran confluencia de códigos hipermediática, y la conformación misma del universo hipermediado, según la expresión desarrollada por Scolari (2008), como aproximaciones a la idea de la formación de un hiperlenguaje: un lenguaje de lenguajes, capaz de integrar y glosar en su gramática universal las formas e interfaces previos de la comunicación humana en todas sus variantes, herramientas y niveles de acción, y que funciona transformando esta gramática universal de la comunicación en nuevas estructuraciones o modulaciones, las ahora denominadas especies mediáticas (Scolari 2015, Manovich 2013), que a su vez, van reconformando y adaptando pragmáticamente las estructuras profundas a las conformaciones superficiales de la comunicación digital. Al fondo de esta teoría, subyacen las tesis piagetianas del desarrollo cognitivo, en las que la integración de la acción en entornos para formar esquemas, simbolizaciones y posteriormente formalizaciones constituye la base de la inteligencia humana. Vamos a explicar en detalle estas tesis.

\section{Recordando la gramática transformacional}

Para entender el interés de esta teoría, es necesario retomar la teoría del lenguaje como gramática transformacional y generativa enunciada a mediados del siglo XX por Noam Chomsky. (1986, 1999). La teoría chomskiana parte de la base de la existencia de una gramática universal del lenguaje humano, asociada a las profundas bases semánticas que, ya las consideremos innatas, ya sean adquiridas externamente, constituyen el fondo de recursos sobre el que se arma el lenguaje.

La gramática universal en el caso del lenguaje de los medios digitales viene constituida por todas aquellas gramáticas comunicativas que un usuario de medios digitales tiene a su disposición por el hecho de haber pertenecido a la cultura de los medios, si entendemos por tal la historia de los medios de comunicación y transmisión de experiencias que, heredada de los tiempos anteriores se asume y asimila en la alfabetización en comunicación que recibimos en nuestra formación y vida cotidiana. El magma profundo de formas al que ha tenido acceso un ciudadano del siglo XXI 
en el mundo comunicativo, sea mediado, sea interpersonal o grupal, en la base de su cultura, constituyen la gramática universal de los medios digitales.

En la teoría de Chomksy esta gramática universal del lenguaje es transformada en las estructuras superficiales que a partir de reglas de selección, combinación y proyección estructural, se van generando por parte del hablante. La genialidad de la teoría de Chomsky parte de la idea de que es la práctica, la actuación, la puesta en marcha de las estructuras profundas en sus transformaciones expresivas concretas, la que va a su vez modificando la lengua. Y esto ocurre porque cada estructura superficial, cada conformación estructural en las frases, textos o emisiones verbales, es una creación única que surge de la aplicación de las reglas de selección sintácticas y semánticas del lenguaje profundo, pero también, y especialmente para nosotros, de las violaciones de reglas, los desvíos y aberraciones, las aplicaciones de analogías y proyecciones metafóricas, y de las adaptaciones parciales y modulares que cada hablante puede generar transformando así la estructura profunda del lenguaje. (Chomsky desarrolla esta tesis en su obra Aspectos de una teoría de la sintaxis (1999).

No entraremos en la polémica entre Internalismo/externalismo que generó esta teoría al discutirse mucho sobre la existencia de una gramática universal del lenguaje, profunda y común, que es transformada y convertida en generativa mediante las creaciones, rupturas, desvíos semánticos, proyecciones y recombinaciones, en la pragmática del lenguaje. No nos afecta ese debate, puesto que nosotros nos vamos a ocupar de un lenguaje de lenguajes cuya gramática universal viene constituida por la memoria de los medios y de las expresiones y tecnologías comunicacionales de toda la cultura. Sin embargo, nuestra tesis es que ese lenguaje de lenguajes funciona exactamente igual que el lenguaje verbal, transformando mediante adaptaciones, proyecciones, desvíos y reconformaciones estructurales dicha memoria universal, constituyendo así el lenguaje digital y sus hipermediaciones. Solamente podemos explicar el dinamismo, creatividad y adaptabilidad acelerada de ese lenguaje digital si lo vemos como una gramática transformacional generativa.

\section{El software y el lenguaje digital como gramática generativa}

Debemos a Lev Manovich el acierto a la primera mirada cuando denominó al fenómeno de la digitalización masiva de contenidos culturales "el lenguaje de los nuevos medios de comunicación" (2005). Efectivamente, y como luego el autor ha desarrollado, nos encontramos ante un nuevo lenguaje unitario, aunque conformado por retazos y módulos, retóricas y gramáticas, glosas e interfaces, provenientes de casi todos los lenguajes comunicativos previos, ante los que el lenguaje digital adopta una posición emuladora, es decir, de traducción y de mímesis. (Manovich 2013).

Como Manovich desarrolla recientemente, la codificación y tratamiento unificado de los datos que generan las distintas simulaciones de medios y lenguajes en la red permite aglutinar en bloques de construcción todo tipo de recursos estilísticos y técnicos, con sus significaciones asociadas. Manovich acentúa la idea de la simulación de esos recursos. Nosotros mostraremos que el mecanismo fundamental para generar esa construcción estructural es la proyección metafórica. El lenguaje digital se estructura mediante metáforas de lenguajes y de medios previos, compartiendo con el lenguaje verbal el núcleo metafórico central que permite su estructura arbórea. 
Esto es absolutamente normal si adoptamos la idea lotmaniana, vygotskiana y perciana, según la cual todo lenguaje es un sistema segundo de señales (Lotman 1988, Peirce 1931-58, Vygotsky 2010), un sistema traductor, cuyos significados últimos son otros signos que constituyen la base del mismo. Los lenguajes verbal, gestual, mediático (asociado a retóricas, estilos y formas de medios, herramientas y tecnologías), kinestésico (asociado al cuerpo, a los lenguajes gestuales y a las experiencias orientacionales, sensoriomotoras etc), procedentes de distintas pragmáticas culturales, que consituyen la base alfabetizante universal del lenguaje de los nuevos medios, son traducidos y simulados, citados y encastrados, en el sistema de señales digital constituido por el conjunto de los textos digitales.

El lenguaje digital que se genera mediante la elaboración del software para su manejo en las interfaces de los ordenadores y la red, es un lenguaje de lenguajes, como ocurre en realidad a todo lenguaje. Se funda, como todo lenguaje, en la hibridación de lenguas anteriores, y de su síntesis se obtiene, aplicando operaciones transformacionales como la analogía, la proyección o la violación de reglas de selección semántica y sintáctica, unas estructuras prácticas nuevas, en constante cambio: las innovaciones digitales que van hibridando modularmente las formas previas.

Manovich (2005) dio en la clave al detectar varias de las operaciones transformacionales y de las macro-sintaxis que construyen los textos de los nuevos medios. El carácter modular de los lenguajes digitales, es decir, el hecho de que se conformen los textos y páginas en estructuras que pueden componerse y encastrarse unas en otras, es igual al carácter estructural de todo lenguaje. Cada estructuración modular nos permite ver y apreciar su composición concreta y al mismo tiempo, las reglas que la han generado o que se han adaptado para su generación. Permite también la combinación creativa y la adopción de nuevas particiones en las estructuras. Exactamente igual que el lenguaje verbal, su naturaleza estructural permite generar significado a partir de la combinación infinita de sus elementos constitutivos, que además mediante esa combinación, forman nuevas estructuras al crear nuevas reglas selectivas. (Chomsky 1999).

La modularidad del lenguaje digital es idéntica al carácter estructural de la gramática transformacional verbal. La estructuración permite combinar creativamente los elementos de una gramática universal ateniéndose a sus reglas, como hace la sintaxis. Pero también, la estructuración permite romper las reglas semánticas y desviar los significados para generar nuevas expresiones, como sabemos por las teorías proyectivas y cognitivas del lenguaje (en particular, por la teoría del desvío semántico de la metáfora (que explicaremos en breve-De Bustos 2000, Black 1966, Lakoff 2000).

La modularidad y carácter ensamblado y construido de un lenguaje está muy relacionada con la capacidad para llevar a cabo operaciones cognitivas muy importantes, que permiten la expresión nueva, la pragmática que transforma la lengua. Lo que apreciamos en el lenguaje de los medios digitales es una incesante capacidad de aprovechar la modularidad para aprender la composición de los textos y mensajes, pero también, para cambiarla, para visibilizar sus reglas de selección y para romperlas generando nuevos fenómenos expresivos. Los híbridos de lenguajes y gramáticas que se generan constantemente en las pantallas digitales rompen constantemente las bases estáticas de sus sintaxis gracias al sistema en bloques, estructural. Con ello, generan nuevas sintaxis y nuevas reglas de selección.

Pondremos un ejemplo para entender este fenómeno en toda su amplitud. Manovich (2013) explica cómo en el nuevo lenguaje de los medios digitales los materiales 
y las técnicas pasan a ser componentes lingüísticos que se funden y reúnen en nuevas "gestalts" (2013: 167) ofreciendo a pesar de su muy diferente proveniencia una coherencia y estructura. Un texto digital, como por ejemplo un reportaje transmedia, puede ser una estructura modular en la que estén encastrados formas como el texto verbal escrito, la imagen en 2D, la imagen 3D, la ilustración, la foto en blanco y negro, y la música de fondo. En la comprensión del texto multilingüístico que subyace a esta página web transmedia, hay un único idioma de fondo, que permite, por ejemplo, que lo que antes era una impresión bidimensional conviva con una expresión sonora y a la vez con una simbolización abstracta proveniente del mundo alfanumérico. Múltiples reglas de selección se rompen en la conformación modular de esta estructura expresiva, como son las reglas de interpretación de lo bidimensional y tridimensional, la codificación de las imágenes planas que conviven con los efectos de profundidad en $3 \mathrm{D}$, o la escalabilidad que determinados elementos presentan, que comparte espacio con el simbolismo de las letras capitulares medievales o los titulares periodísticos estáticos en clave. Pero en tanto es posible incorporar estos elementos en un único texto, el mismo puede ser leido, comprendido y adoptado por el hablante del lenguaje digital. La modularidad permite saltar de plano expresivo o de gramática previa, y al mismo tiempo, mantener un conjunto. Todo lector que accede al reportaje transmedia lo explora y aprende su estructura modular. Se ha creado, con ello, un género nuevo, que será sin duda modificado en breve tiempo, en cuanto en su composición creativa se innoven e introduzcan nuevos elementos proyectados.

No solamente ocurre así. El hablante del lenguaje digital que accede a la conformación modular de las formas comunicativas ensambladas, mediante los adecuados desvíos, proyecciones, analogías y rupturas de plano, se alfabetiza en este lenguaje y pasa a ser un creador activo en el mismo: por eso el lenguaje de los medios es llamado "intuitivo", en tanto su competencia nos habilita a generar nuevos usos y combinaciones, demostrando así que el uso puede cambiar los distintos medios y técnicas, es decir, la "performance" puede y de hecho afecta a la "competence" del lenguaje de los nuevos medios, en el que todo hablante es un potencial creador del mismo: por eso los usuarios pueden ser "produsers", es decir, creadores de nuevas modulaciones y estructuras mediáticas digitales.

La tensión innovadora del lenguaje digital está en dos puntas: por un lado, los creadores e innovadores artísticos, como los videoartistas, los escritores de literatura hipertextual e hiperpoesía, y otros artistas cuya función fundamental, como sabemos desde McLuhan, es adaptar la tecnología al equilibrio sensorial y cultural ideal. La otra punta de innovación está en los usuarios convencionales, que con su uso transforman los nuevos medios digitales puesto que afectan a la gramática que los conforma y generan nuevas construcciones y objetos con ellas: exactamente igual que en el lenguaje verbal, la creación es por una parte universal y anónima, a la par que de los creadores y artistas literarios.

\section{EI lenguaje digital. Mecanismos fundamentales}

Así pues, el lenguaje digital, como gramática transformacional, adopta la forma fundamental de una estructura de base universal conformada por las técnicas, gramáticas y glosarios de las formas comunicativas y sus herramientas, que es constantemente 
transformada en estructuras modulares de composición visible, cuya ensamblabilidad nos permite apreciar y aprender su sintaxis, mostrar su factura y sus reglas de selección, y sobre todo, nos permite acceder al mecanismo traductor y proyectivo que abre a todos los hablantes digitales la generación de nuevas actuaciones.

Debe verse, por tanto, la estructura de las construcciones procedentes de distintos medios y lenguajes previos, y su clara referencia, como un mecanismo ostensorio del hiperlenguaje. La simulación, la emulación de todos los medios previos, es decir, el denominado fenómeno de la "re-mediación" (Bolter 2011, 1999) es parte fundamental de este lenguaje. El reciclaje de elementos es clave en este sistema traductor, como todo lenguaje. Pero además, también es un sistema hipermediado: es necesario dejar visible su glosario, y mostrar la construcción de sus ensamblajes, para que todo hablante pueda acceder a las traducciones que realiza en las estructuras de interfaz de los ordenadores y pantallas, e incluso generar las suyas propias.

El mecanismo más fundamental de todo lenguaje, como la lingüística cognitiva ha venido estudiando desde hace casi un siglo, es la analogía estructural y la proyección metafórica. Chomsky, en su teoría semántica, establece que en el lenguaje tiene lugar una constante adaptación y estructuración mediante la proyección de reglas en contextos nuevos, lo que hace que el niño que aprende a hablar vaya acertando o errando en la aplicación de las reglas y su sucesiva instrumentación. Para guiarse, el niño realiza analogías, es decir, aplica reglas conocidas de situaciones previas a nuevas necesidades expresivas.

En la metáfora, el lenguaje aplica reglas y estructuras significacionales a contextos diferentes a los originales mediante la llamada proyección cognitiva. Como se descubrió al estudiar la teoría cognitiva de la metáfora (Black 1966), las proyecciones semánticas no son solamente propias del mecanismo metafórico, sino que en realidad, y como Chomsky ya previó, son el núcleo de conformación de muchas estructuras semánticas. Las metáforas permiten visibilizar y conceptuar objetos en términos de otros, creando subconjuntos de lenguajes, dominios o léxicos, de modo que constituyen el núcleo esencial de la lengua y de muchos sistemas signicos. A esa idea tan genérica llegaron cognitivistas como Lakoff y Johnson (2000).

Black (1966) explicó con claridad cómo la proyección cognitiva permite aplicar estructuras y nodos de conformación de significados a contextos diferentes, generando así nuevas estructuras, campos léxicos adaptados y con ello genera visibilizaciones de contextos abstactos o sin parangón. El lenguaje, según las ideas de Chomsky y Black, está constantemente adaptando bloques lingüísticos a nuevos contextos, por mecanismos de ensamblaje proyectivo. Estos mecanismos son los mismos que hallamos en el lenguaje digital multimedia de los entornos de software.

La teoría cognitiva de la metáfora, que posteriormente se desarrolló en su enfoque corpóreo/experiencial (Lakoff Johnson 2000), aportó el mecanismo fundamental de la proyección y el establecimiento de alineaciones estructurales para cartografiar, limitar y definir nuevos campos semánticos. Lakoff añadió como mecanismos proyectivos los dominios estructurales generados por experiencias corporales, espaciales, orientacionales, y relacionadas con herramientas, contenedores, y medios. La proyección dejó de ser meramente verbal para ser considerada una operación cognitiva más allá del lenguaje verbal, que tenía, entre sus matrices metafóricas más esenciales, formas kinestésicas, herramientas estructurales generadas en la observación visual del entorno, o metáforas ontológicas asociadas a objetos y procesos de muy diferentes mundos de experiencia. 
Ni que decir tiene que este mecanismo lingüístico es análogo al que Piaget detectó en el desarrollo de la inteligencia en el niño, con la elaboración de esquemas a partir de la interiorización y acomodo de los esquemas de acción y movimiento en el entorno, que poco a poco van introyectándose para constituir estructuras más complejas, abstractas o formalizadas. (Piaget 2000, 1961).

Piaget creo la primera teoría transformacional para el desarrollo de la inteligencia, y en él se inspiró Chomsky. Su aportación es crucial en nuestra tesis, porque el autor vio la transición y continuidad entre las fases tempranas de relación del niño con el entorno, con la elaboración de esquemas de acción, y el desarrollo transformativo posterior de las representaciones, abstracciones y desarrollos simbólicos. En nuestra tesis, el lenguaje digital es un ejemplo palmario de cómo la interacción con tecnologías y objetos previos asimila, acomoda y transforma esos esquemas de actuación, constituyendo una lógica mosaica de elementos unidos por un desarrollo cognitivo análogo al que tiene lugar desde la acción en el entorno real a la simbolización y formalización. Es muy curioso que el entorno digital reproduzca el desarrollo transformacional que se da en la maduración cognitiva. Es como si con esa gramática transformacional, aprendiéramos a generar una inteligencia adaptada al medio digital, y así es.

El mecanismo fundamental del lenguaje digital es éste precisamente: la proyección cognitiva que permite ensamblar una estructura significacional proveniente de un entorno ajeno a dicho lenguaje (por ejemplo, la estructura del manejo de las flechas visuales como signos índices para llegar a objetos o para identificarlos en la siñaléctica offline ) que fundimos con otra proveniente de otro diferente (por ejemplo, la estructura del manejo prensil de la mano sobre un objeto tridimensional para desplazarlo y hacer cosas con él), de cuya fusión conceptual puede surgir, en su plasmación bidimensional sobre el monitor, la interfaz del ratón y puntero de la pantalla, que es también un elemento del glosario del lenguaje digital, al que a su vez que podemos ver luego encastrado en múltiples formas - incluso, en las pantallas táctiles como simple "cita" y asociado a otras acciones, como la flecha activa que sirve para el envío de mensajes.

El caracter transmediático o como acertó Scolari a definir, "hipermediado" de las transformaciones del lenguaje digital es una lógica consecuencia de los mecanismos proyectivos constantes y continuos. La hipermediación (Scolari 2008: 113:) es "un proceso de intercambio, producción y consumo simbólico que se desarrolla en un entorno caracterizado por una gran cantidad de sujetos, medios y lenguajes interconectados tecno-lógicamente de manera reticular entre sí". Dicha hipermediación es la interposición de estructuras como interfaces que, cartografían y aportan herramientas, glosarios y léxicos en un proceso comunicativo. Lo que nos encontramos en el lenguaje digital es la aplicación universal del principio transformacional: toda estructura generada por medios, herramientas y lenguajes es interpolable para generar otra.

Cada texto y cada producto del lenguaje digital muestra la capacidad de proyección y de metaforización del mundo comunicativo con sus propios componentes. $\mathrm{Si}$ como McLuhan profetizara, el medio es el mensaje, los mensajes digitales generan medios nuevos porque provocan hipermediaciones constantes, materializando cada vez más la semiosis ilimitada peirciana.

De las tres gramáticas que Scolari (2004: 105) detectó tempranamente interactuando en las interfaces, (gramáticas del texto, de la interacción y de la página) 
los principios que aquí indicamos de proyección permiten cambiar de plano entre ellas, unificándolas y descomponiéndolas o reensamblándolas modularmente. El abatimiento de planos generado por las transformaciones hace que se unan las tres gramáticas, y que lo que pertenece a un dominio pase a ser estructura de otro. Un medio o un elemento de un medio se libera, como dice Manovich, de su "hardware", para ser ya una metáfora organizativa que permite ensanchar el espacio digital, y enlazarlo con los espacios comunicativos previos.

El desarrollo del lenguaje digital es un gigantesco espacio proyectivo que trabaja mediante la generacion constante de innovaciones por aplicación de analogías, alineaciones estructurales y cambios de plano metafóricos a partir de una base universal de lenguajes y medios de comunicación previos. Igual que la gramática universal del lenguaje alfabetizaba profundamente al hablante para que pudiera llevar a cabo sus "performances" expresivas, la gramática de los medios y lenguajes alfabetiza básicamente al usuario digital para que interprete y aplique las proyecciones adecuadas en la página intuitiva de una web o pantalla. Este lenguaje admite un desarrollo creativo individual, exactamente igual que la gramática transformacional lingüística. Como el lenguaje verbal, el lenguaje digital es generativo, se transforma constantemente y sus herramientas son las operaciones cognitivas que puede realizar con las gramáticas, técnicas y medios previos. Su infinito y acelerado desarrollo, que genera cada vez más elementos "transmedia", sólo se explica por los ilimitados fenómenos de proyección metafórica que se generan en su léxico, y que permite trasponer experiencias en herramientas y viceversa.

Una pieza clave igualmente esencial es la fusión conceptual (Fauconnier 2005) operación cognitiva más común todavía que la proyección metafórica. La fusión conceptual permite ensamblar, gracias a la estructural modularidad de un lenguaje, elementos dispares e inconciliables en bloques de significación y valor pragmático. Las fusiones conceptuales nos permiten ensamblar múltiples planos en un sólo conjunto. Un ejemplo fácil de ver es el escritorio de un sistema operativo, en el que conviven en fusión cognitiva naturalmente aceptada por los usuarios elementos provenientes de muy diferentes planos de significación y contexto comunicacional: un tapiz o alfombra, una mesa o escritorio del mismo tamaño, una papelera de reciclaje diminuta, una flecha móvil bidimensional, letras capitulares de movimiento autónomo, iconos que simulan papeles o carpetas de reducido tamaño, un reproductor de imagen gigante, una foto personal que ocupa el fondo a manera de escenario mental, etc, etc.

Las reglas de composición implicadas en el uso y competencia ante un escritorio de ordenador nos permiten una transpolación de y a otras pantallas e interfaces: el mismo lenguaje de glosas, donde encontramos procesos, resultados, herramientas, símbolos, de múltiples contextos comunicacionales, sean tridimensionales, bidimensionales y simbólicos, abstractos o puntuales y concretos, se encuentra en otras situaciones digitales.

Muy clara es la fusión conceptual que ha permitido, recientemente, la incorporación de las interfaces táctiles a pantallas y tabletas de todo tipo. Con el software de los dispositivos táctiles el medio digital incorpora, proyecta, simula y funde el lenguaje kinestésico táctil corporal, así como muchas de sus metáforas experienciales básicas, con otros planos metafóricos previos como son los asociados a cinematismo, ilusionismo visual, animación ilustrada, etc. Las fusiones de elementos en estas estructuras y herramientas no dejan de desarrollarse constantemente. Su gramática universal bebe, en este caso, del mundo proyectivo de las herramientas corporales, 
orientacionales, kinestésicas, que se funden sin problema con efectos o ilusiones de movimiento y perspectiva. El manejo del dedo sobre la pantalla táctil simula operaciones tridimensionales en la bidimensionalidad, haciendo una traducción proyectiva: desechar un archivo se logra empujándolo hacia fuera de la pantalla, y mientras lo desplazamos, el objeto en cuestión se ilumina o se resiste al movimiento como si estuviera imantado, de modo que si lo "soltamos" despegando el dedo de la pantalla. vuelve a su lugar primero.

Pensemos en la cantidad de fusiones conceptuales asociadas a una página de periódico online, donde los códigos, guiños y glosas de otros lenguajes de medios -el cómic, la página en papel, la imagen cinemática, la foto estática, el hipertexto, están recombinándose en nuevas formas. Cada una de las nuevas reconfiguraciones muestra sus reglas de modulación y permite el acceso a su pragmática, a su uso. Recientemente se incorpora una nueva estructura de la web para los diarios digitales, en disposición horizontal, de modo que leemos las noticias tocándolas y arrastrándolas de izquierda a derecha. Es una proyección metafórica del mecanismo de pasar la página del diario en papel, pero también, recuerda a la secuencia de la tira cómica tradicional, y por último, también re-meda el retorno mecanográfico de los textos, horizontal y de izquierda a derecha en la cultura occidental.

En último lugar, y tal como Manovch (2005) detectó y desarrolló tempranamente, uno de los mecanismos hipergramaticales del lenguaje digital en su conjunto es la proyección escalable. Vamos a explicar detenidamente este elemento de la gramática universal digital, porque su matriz cognitiva es probablemente la más esencial de este nuevo y avasallador lenguaje.

\section{La matriz metafórica del lenguaje digital: el mapa escalable}

Si hay un elemento que identifica y está presente en absolutamente todos los contextos del lenguaje digital, como una gran matriz metafórica, es la estructura del mapa escalable.

Como Manovich detectó, la escalabilidad es un conjunto de elementos cognitivos proveniente de diversos entornos culturales clave en la cultura comunicativa universal. Los mapas son curiosos dispositivos cuyos componentes y reglas operativas nos permiten proyectar y organizar la información permitiendo la disminución de la carga cognitiva, puesto que los mapas permiten la conexión entre codificaciones abstractas y codificaciones detalladas. Los mapas nos permiten pasar, digamos, de la comunicación analógica a la digital, de lo infinitesimal y gradual a lo simplificado y esquemático y además nos permiten el cambio de plano secuencializado. Esto quiere decir que el mapa realiza en la mente humana la fusión conceptual entre representación esquemática y acceso al objeto representado en todo su detalle, por virtud del proceso interpretativo. Esta operación del mapa tradicional, por la que este curioso objeto significativo permitía fundir analógico y digital mediante la proyección mental adecuada, se convierte en el gran simbolo operativo del lenguaje y la inteligencia digital. Se trata de la gran gramática transformacional que permite operar en la red: como afirma Manovich ya en 2005, "si deseamos describir lo que los nuevos medias hacen en una sola palabra, con todos los viejos medios, una buena opción es el término "cartografiado" o proyección". (Manovich 2005a) 
La escalabilidad, la operación de reducción o ampliación de una representación, con la consecuente alteración de la información que arroja, es una matriz cognitiva de enorme importancia en la cultura. Pero más aún en el ámbito del lenguaje digital, puesto que en su núcleo esencial la digitalización abstracta permite reducir la complejidad del mundo analógico y gradual, complejo e inabarcable, a la codificación binaria por lo que el mapa, diverso al territorio, es el gran símbolo del universo digitalizado.

En el medio digital se produce la numeralización y codificación en un lenguaje tecnológico unificado. Este sencillo hecho, señalado por Manovich por su importancia cultural, es el "quid" de la cuestión, puesto que la digitalización crea el medio para jugar con las representaciones en pantalla aportándoles la dimensión graduable o escalable. Ello pone las bases para que en el diseño de muchísimos elementos y formas de la web se adopte una naturaleza escalable, y que múltiples elementos, objetos o formas puedan desplegarse como los mapas.

Proyectando esta capacidad de la tecnología digital en estilos y formas, surge un universo cuya operación básica es la desplegabilidad y el repliegue, en el que existe una "profundidad" por la que bucear, y donde cualquier mensaje u objeto, de ser un contenido, pasa a ser un medio, al transvertirse en mapa.

La escalabilidad ha generado una serie de gramáticas esenciales en el lenguaje de los medios. Es uno de sus grandes mecanismos organizativos: el modo como asociamos y jerarquizamos información en el lenguaje de los medios digitales es mediante dispositivos proyectivos que despliegan o repliegan información.

El manejo y despliegue de un mapa nos conecta a dos tipos de experiencia básicos para entender el medio digital. Por un lado, tenemos una experiencia de acceso a proyecciones simples, de baja carga semántica, en cuya coherencia interna, sin embargo, reposa la organización de amplísimas cantidades de información si desarrollamos la analogía estructural y proyectamos el mapa sobre el territorio, es decir, en el contexto digital, si desplegamos el mapa mediante los vínculos que éste tiene con el territorio, es decir, con el universo de los datos.

La escalabilidad es la operación que evidencia la digitalización de toda representación en los nuevos medios. En su pragmática está evocada la infinita capacidad de emulación del lenguaje binario. En su desarrollo también estructural se aprecian las reglas de composición de las representaciones en estos medios. Es la gran práctica indicial, que nos conduce, a la naturaleza de fondo de los medios digitales.

La metáfora del mapa es la matriz del hipertexto y su estructura, donde adquiere un significado nuevo. Los vínculos y enlaces entre textos son proyecciones escalables que asocian información con distinto grado de detalle. En muchos casos, los vínculos en los textos digitales, una vez accionados, se despliegan en textos detallados y completos. Así, transponen al medio textual la escalabilidad propia del mapa visual, como ya hacían, aunque mediante nuestra memoria semántica, los diccionarios y glosarios impresos. Por eso se dice que los hipertextos son, y seguimos generando metáforas, "textos tridimensionales" (Rodríguez de las Heras 1991)

Más allá de este modelo simple, los vínculos entre textos dispares también establecen nexos expresivos y configuran mapas o gestalts de los mensajes, con acentos o elementos expresivamente densos, como ocurre en la novela hipertextual (Pajares 2015). La unión de todos los textos mediante enlaces y representaciones cifradas y simplificadas permite establecer estructuras de relación, reducir la carga cognitiva que implica la información mediante su jerarquización en mapas, plantear la necesi- 
dad de proyectar constantemente y generar nuevas analogías que ordenan y cartografían contextos, y jugar de nuevo con el concepto de mapa como interfaz y tambien como metáfora que rompe las reglas de coherencia al fusionar planos distintos de representación entre sí.

En el lenguaje hipertextual, la escalabilidad nos permite unir la macrosemántica del lenguaje verbal- las estructuras generales, la memoria a largo plazo, la organización de los datos masiva e universal- con la información episódica y las estructuras detalladas y concretas donde aparecen los enlaces. Cada vínculo escalable acciona el posible acceso a la memoria semántica de la información mediante el despliegue de los datos en navegación por los textos. Pero a diferencia del proceso pre-digital, en el que el acceso a la memoria era enteramente intrapersonal, psíquico e impalpable, aquí es posible externalizar y materializar ese acceso. Es por tanto una transposición, una materialización del proceso de acceso a la cognición representada en el vínculo escalable.

Lo que los mapas digitales hacen es materializar el proceso de abstracción, o su reverso, de desarrollo hacia el medio analógico, gradual infinitesimal. También, la reversión de ese proceso nos visibiliza el encriptado y cifrado de la memoria en representaciones simples. La forma de lectura hipertextual digital, a diferencia de la lectura impresa tradicional, recurre de muy diferente forma a la memoria de trabajo y a la memoria a largo plazo. El uso de la memoria extensa, semántica y de grandes estructuras, es menos necesario. La memoria semántica está materializada en la navegación hipertextual, en el medio de los enlaces escalables. Sin embargo, la memoria a corto plazo y de trabajo se ve mucho más exigida, por la necesidad de manejar enormes cantidades de información inmediata, cambiante y de difícil abarcabilidad. Las proyecciones nos permiten tener presente ambas cargas cognitivas, y metaforizan su alternancia. La metáfora que nos orienta y alfabetiza en este constante procedimiento es la del mapa.

Los mapas escalables admiten como decimos reversibilidad proyectiva, es decir, pueden desarrollarse de lo simplificador y abstracto hacia lo complejo y en detalle, o viceversa, abstrayendo elementos, generarse como asociación de elementos simplificados. La red genera constantemente ambos procesos, y los invierte, como metáfora organizacional y experiencial de su gramática universal. Un elemento, símbolo, palabra, imagen o texto enlazado es siempre un nodo de un mapa, sea un mapa ya existente, sea un mapa en progreso, que se genera con la lectura o la navegación. El modo como se acumula o se desarrolla información siempre sigue el protocolo proyectivo del mapa. Es posible generar infinitos itinerarios en la navegación digital, y con ello, generar mapas que crean territorios cognitivos nuevos.

Cualquier elemento digital, por su propia conformación de imagen generada a partir del lenguaje digital, permite convertirse en navegable, es decir, en un mapa. Del mismo modo que, como hemos indicado, todo mensaje genera una estructura, esa estructura puede convertirse en un mapa sobre el que se navega, transformando a cada nuevo mapa el lenguaje digital.

\section{Metáforas, proyecciones y fusiones de la gramática universal digital}

Para descender al plano más concreto e ilustrar esta teoría, vamos a ejemplificar, a partir de los previos trabajos de Manovich y Scolari en medios digitales, y de las 
teorías cognitivas y lingüísticas de Chomsky, Black y Lakoff, sobre todo, algunos de los recursos fundamentales de la gramática universal digital. En seguida quedará claro que esta gramática contiene elementos y dispositivos selectivos provenientes de muy diversos subuniversos simbólicos comunicacionales:

\section{Métáforas fundamentales}

- Metáfora del contenededor (orientacional, experiencial, ontológica). Su descubrimiento es debido a Lakoff. Esta gran matriz organizacional cartografió las primeras organizaciones de datos informáticos, y hoy es una gran clave semántica y regla de analogía en el lenguaje digital. Un enlace, un objeto señalado, es siempre un contenedor de información. La exploración de contenedores en un espacio web es un modo habitual de acceso al mismo. La alfabetización básica en cualquier interfaz requiere conocer su estructura de contenedores, que pueden ser múltiples y recurrentes. El sistema "Windows" de ventanas, el MSDos de carpetas y archivos, son organizaciones basadas en la metáfora del contenedor. Se trata de una metáfora ontológica que está en la raíz de nuestra experiencia vital primordial.

- Metáfora del mapa escalable (ontológica metacognitiva), a partir de las investigaciones de Max Black y de Mary Hesse. El mapa que une dimensiones analógica y digital, que admite distinta carga semántica según su despliegue o repliegue, y que introduce y enseña la dinámica proyectiva en cualquier objeto, es una gran matriz gramatical en la red, que desvela su naturaleza emuladora. Hemos convertido en escalables todos los elementos, y ello nos ilustra sobre el carácter hiperconectado de todos los datos.

- Metáfora cinética y cinemática (movimiento de objetos, desplazamientos, retóricas de movimiento), ampliamente estudiadas por Manovich, han sido grandes matrices para asimilar y crear estructuras de analogía en los espacios digitales. Las metáforas cinéticas generan también espacio, temporalizan la comunicación y son vitales en los nuevos estilos narrativos. Están muy relacionadas con las experiencias culturales asociadas a la imagen cinematográfica, ilusión de movimiento, traslado de objetos, sistemas de desplazamiento, accionamiento de dispositivos de rueda, etc etc pero últimamente también a la expresión del movimiento con emulaciones de operaciones de movimiento táctil, de rotación de objetos, etc. que vemos ahora mismo.

- Metáforas kinestésicas y táctiles (experienciales, corpóreas, espaciales), a partir de las ideas de Lakoff y Johnson. Matrices metafóricas de las experiencias táctiles, corpóreas, kinestésicas, organizan las reglas proyectivas fundamentales de las nuevas interfaces digitales (tocar, lanzar, desplazar, pinzar, pinchar), en múltiples glosas, bidimensionales, tridimensionales, etc. La incorporación de esta matriz metafórica al lenguaje digital muestra hasta qué punto es variopinto e híbrido su mecanismo de ensamblajes de lenguajes y herramientas previas. El espacio transdimensional generado en el lenguaje digital es posible por ser éste un lenguaje transformacional, estructurado y modular, y generativo. Esta capacidad del lenguaje digital reproduce en su entorno los procesos cognitivos básicos de introyección, asimilación y acomodo de esquemas de acción con objetos, que se dan en la formación de la 
inteligencia, como estudió Piaget. Este proceso se ve "glosado" y emulado en el lenguaje digital.

- Metáforas orientacionales/ espaciales (Lakoff), muy esenciales en la proyección del espacio web, a partir de la idea de mapa,y sobre todo, en las fusiones espaciales/temporales que organizan las narraciones, la secuenciación de la información, e incluso estructuras complejas como la construcción del espacio $3 \mathrm{D}$, ilusionismo creado a partir de la perspectiva teatral y el trucaje mediante paneles o maquetas. El uso ostensorio de estas metáforas y su composición siempre hibridada con otros planos significacionales es clave en la red.

- Metáfora de la construcción (experiencial corpórea, piagetiana), a partir de las ideas de Lakoff y Piaget, es la responsable de la gramática de la modularidad que permite ensamblar elementos en estructuras para generar nuevas asociaciones y ampliar las reglas de selección. Es la clave, paradójicamente, del crecimiento de las fusiones conceptuales que abaten y sincretizan mensajes y medios, herramientas y contenidos, retóricas y episodios. Muchos juegos en la web para niños o adolescentes ejercitan metáforas constructivas modulares (Minecraft), así como también espaciales multidimensionales, cinéticas, etc. Nótese que esta gran metáfora fundamental es la análoga al carácter estructural del lenguaje, y es la que permite la generatividad y creatividad expansiva del mismo. Es también la que hace que el medio digital tenga aspectos de trucaje, carpintería visible y teatralidad que nos muestran su carácter fabricado.

\section{Proyecciones fundamentales}

- Proyecciones de los medios: los lenguajes, motivos y estilos de todos los medios anteriores que son simulados y proyectados total o parcialmente en el lenguaje digital: la "cita" del lenguaje cinematográfico, la "glosa" de la perspectiva teatral, la incorporación del estilo novelesco lineal, o la emulación de la página de periódico modular constituyen ejemplos de un fondo universal mediático que es constantemente proyectado y fundido a la web.

- Proyecciones de las técnicas: los fragmentos o totalidades de técnicas de todo tipo relacionadas con la comunicación en amplios escenarios culturales, de la tecla de retorno de la máquina de escribir a la tecla con una flecha del reproductor de video, de la cara del "smiley" de la cultura hippie o psicodélica al auricular del teléfono fijo tradicional. Elementos técnicos muy parciales pueden ensamblarse en otros textos y funcionar en ellos perfectamente: es el caso de la flecha simuladora del reproductor de video sobre una imagen digital, o el cambio de color para seleccionar elementos que proviene de las técnicas fotocompositivas, incorporado a las pantallas táctiles. Las técnicas y herramientas se convierten en palabras y secuencias cognitivas del lenguaje digital también.

- Proyecciones de estructuras espaciales no digitales: cartografían y estructuran grandes dimensiones de actuación, organizaciones como la casa, el jardín, el océano, el mar, el universo celeste. Metáforas y proyecciones cognitivas de experiencias en espacios off line son vitales para entender y desarrollar el espacio paralelo digital. Las fusiones entre estos elementos son notorias. 


\section{Fusiones conceptuales}

Hibridaciones indefinidas y múltiples en las que medios, lenguajes y tecnologías emulados se funden mediante la estructura modular, y a partir de la idea de la proyección analógica. La clave para la fusión es que todo medio puede encastrarse en otro si mediante él se accede a información. Multimetáforas y proyecciones sobre proyecciones son el idioma básico del lenguaje digital. Basta reconocer y ensamblar, mediante una modulación proyectiva, estas formas provenientes de otras estructuras, para poder tomar la iniciativa en el lenguaje digital.

\section{Conclusiones}

La concepción del lenguaje digital como una gramática generativa nos permite entender la evolución acelerada de sus transformaciones.

Estas transformaciones son producidas por la aplicación de una serie de operaciones generativas posibles gracias a la estructura modular del lenguaje digital, que incorpora en su desarrollo los glosarios, reglas de selección y de combinación de una gramática universal de la comunicación y sus técnicas. Pero especialmente, el lenguaje digital permite la aplicación de las operaciones cognitivas profundas, de proyección, fusión conceptual, y desvío semántico, a partir de matrices metafóricas fundamentales idénticas a las que funcionan en el lenguaje verbal.

Al igual que en la gramática transformacional, el lenguaje digital transforma mediante la ruptura de sus propias reglas de coherencia selectiva el universo de los lenguajes generados por todas las herramientas y técnicas de la comunicación, de la comunicación interpersonal gestual al lenguaje teatral, del lenguaje de la perspectiva lineal al del mapa de Gps. Abierto al cambio generado por el uso, es decir por la performance, el lenguaje digital es más creativo que ningún otro medio previo puesto que no solamente se beneficia del uso creativo individual, sino del generado por los creadores artísticos y por los desarrolladores tecnológicos, que cooperan con todos los usuarios.

Hay entornos artísticos y creativos especializados en extender indefinidamente la gama de versatilidades de este lenguaje generativo. La novela hipertextual, o la hiperpoesía, son ejemplos de expresiones artísticas en las que el objetivo final es la definición nueva de estructuras, protocolos comunicativos, lenguajes hibridados. Todo el objetivo de la creación es precisamente reequilibrar la extensión tecnológica para encontrarle su mejor uso. Las vanguardias artísticas en este lenguaje están creando constantemente experiencias nuevas para su reciclaje en el mismo. El mapa escalable de la web admite una versión cuántica en la que él mismo genera un territorio: las operaciones del lenguaje digital lo recrean y extienden constantemente. Pero así funciona también el lenguaje verbal, como sabemos desde la teoría de Chomsky.

El concepto de interfaz es clave para entender cómo se establece en el lenguaje digital un puente entre planos tan distintos del universo comunicativo como son las herramientas y los contenidos. Cualquier contenido, en la gramática universal digital, puede convertirse en una interfaz, es decir, ser un puente que mediante una estructura escalable nos da acceso a otros contenidos. La capacidad de utilizar las herramientas, las expresiones materiales, como metáforas esenciales de expresión, o 
como glosas que nos dan acceso a operaciones o nuevas presentaciones de elementos, es un ejemplo de la versatilidad y capacidad transformativa de este lenguaje.

En el lenguaje digital, todo recurso expresivo, sea herramienta o contenido, sea significante o significado, es una pieza constructiva. El ilusionismo, la teatralidad, la carpintería visible de la construcción de este lenguaje es artificial y fabricada porque este lenguaje debe mostrar su factura, debe animar a la composición generativa, y debe mostrar incluso las operaciones de analogía, desvío cognitivo, y ruptura de reglas selectivas o de coherencia, encaminando al usuario al aprendizaje de su estructura en progreso constante.

El lenguaje digital reconstruye constantemente su gramática general porque crea sobre sus propios elementos, innovando y ensanchando sus proyecciones y metaforizaciones. Sus estructuras finales son siempre provisionales, en constante desarro1lo. Ello ha hecho que los usuarios de este lenguaje nos acostumbremos a innovar constantemente formas e interfaces a partir de recuperaciones de la memoria de los medios, lenguajes y pragmáticas precedentes.

El sistema traductor de este lenguaje nos propone, a cada nueva interfaz de usuario, una nueva interpretación de la gramática universal de la comunicación y sus herramientas culturales. Hay una analogía profunda entre los medios y los lenguajes. El lenguaje digital obliga a retomar constantemente esa analogía, haciendo de la experiencia y de la cognición un dispositivo que sirve a la posibilidad de manejar todos los datos transcodificados en el sistema informático. Las simulaciones de este lenguaje, como dice Lev Manovich, han liberado la creación y la interacción mediáticas de sus respectivos programas de origen, de sus tecnologías de base. (2013: 200). Al convertirlas en metáforas, y encastrarlas en un discurso más amplio, el lenguaje digital dialoga con todas las costumbres comunicativas convirtiéndolas en recursos de su glosario. Y de ese diálogo surgen formas creativas aceleradamente variadas y novedosas.

El lenguaje convencional y el pensamiento humano siempre han proyectado y transpuesto experiencias provenientes de diferentes contextos para dar forma a las ideas, para aportar energía al flujo de las palabras, para encauzar la actividad de la conciencia humana.

El lenguaje digital materializa y externaliza más si cabe esa capacidad proyectiva esencial y la pone en movimiento para facilitar y promover la comunicación, dando lugar a un torrente de innovaciones en el medio comunicativo que está también desarrollando y moviendo la creatividad humana.

\section{Bibliografía}

Bolter, David J., "Inmediatez, hipermediación, re-mediación”. en CIC Cuadernos de Información y Comunicación, número 16, 2011, pp.29-57. Trad. de un capítulo del texto Remediation. Cambridge, MIT Press, 1999.

Black, Max (1966).Modelos y metáforas. Madrid: Tecnos.

Chomsky, Noam (1986): El lenguaje y el entendimiento. Barcelona, Seix Baral. ASpectos de la teoría de la sintaxis. Barcelona, Gedisa, 1999.

De Bustos, Eduardo (2000).La metáfora. Ensayos transdisciplinares. México, Fondo de Cultura Económica. 
Fauconnier, Gilles (2005), "Fusión conceptual y analogía", en CIC Cuadernos de Información y Comunicación, numero 10, 151-170. Traducción de su texto en el volumen The Analogical Mind, editada por Dedre GENTNER, Keith HOLYOAK y Boicho KOKINOV, Cambridge, Mit Press, 2004, pág. 255-287

Lakoff. George, y Johnson, Mark, Metáforas de la vida cotidiana. Madrid, Cátedra, 2005. Lotman, Juri (1998). La semiosfera. La semiótica de la cultura. Madrid, Cátedra.

Manovich, Lev, 2005a: "Understanding Meta-Media", 1000 Days of Theory: Arthur and Marilouise Kroker, Editors. Date Published: 10/26/2005 www.ctheory.net/articles.aspx?id=493

(2005): El lenguaje de los nuevos medios de comunicación. Barcelona, Paidós, 2005.

(2013):El software toma el mando. Barcelona, UOC, 2013. Softbook en http://softwarestudies.com/softbook/manovich_softbook_11_20_2008.pdf, consultado el 10 de marzo de 2015.

Pajares Tosca, Susana, "La cualidad lírica de los enlaces", revista Especulo, consultada el 12 de marzo de 2015 en http://pendientedemigracion.ucm.es/info/especulo/hipertul/link.htm

Peirce, Charles Sanders (-" (C.P 2.303).) (1931-1958) Collected Papers (C.P), vol 1-8. Electronic Edition de J. Deely, Intelex Charlottesville.

Piaget, Jean (200) El nacimiento de la inteligencia en el niño. Barcelona, Crítica.

(1961) Formación del símbolo en el niño.Formación, juego y sueño. Imagen y representación. México, Fondo de Cultura Económica.

Rodríguez de las Heras, Antonio(1991) Navegar por la información. Madrid, Fundesco.

Scolari, Carlos (2008): Hipermediaciones. Elementos para una teoría de la comunicación digital interactiva. Barcelona, Gedisa..

(2015) Ecología de los medios. Entornos, evoluciones e interpretaciones. Barcelona. Gedisa.

(2004): Hacer click. Hacia una socio-semiótica de las interacciones digitales. Barcelona, Gedisa.

Tato, Juan Luis (1975) Semántica de la metáfora. Elche, Instituto de Estudios Alicantinos.

Vygotsky, Lev (2010). Pensamiento y lenguaje. Barcelona, Paidós. 